\title{
Erratum to: The Old Book Switcheroo: Or Anatomy of a Delusion
}

\section{David Bittner}

\section{Erratum to: J Relig Health DOI 10.1007/s10943-009-9314-2}

Folksinger Mary Travers, of "Peter, Paul, and Mary" fame, died on Sept. 16, 2009, in a Danbury, Connecticut hospital after a long battle with leukemia. She was 72. In this article, Travers is mentioned in connection with her philo-Semitism and advocacy of Jewish causes as an "honorary Jew," an example of someone who might be described by the French word, "juifatre." The apostrophe to Travers should, of course, have referred to her as "the late" Mary Travers.

The author and editor regret the error and express their hope that Ms. Travers may rest in well-deserved peace.

The online version of the original article can be found under doi:10.1007/s10943-009-9314-2.

D. Bittner $(\bowtie)$

Florida Atlantic University, Boca Raton, FL, USA

e-mail: davidbitt2001@juno.com 